\title{
Body Image at Postpartum: Being Overweight but Not Noticing!
}

\author{
Rebecca Cherono $^{1}$, Peter Chege ${ }^{1, *}$, Judith Kimiywe ${ }^{1}$, and Irene Ogada ${ }^{2}$ \\ ${ }^{1}$ Department of Food, Nutrition and Dietetics, Kenyatta University, Kenya \\ ${ }^{2}$ Department of Human Nutrition, St. Francis Xavier University, Canada

\begin{abstract}
*Corresponding author: Peter Chege, Department of Food, Nutrition and Dietetics, Kenyatta University, Nairobi, Kenya, E-mail:chegepeterm@ gmail.com
\end{abstract}

Received: 19 Jun, 2019 | Accepted: 27 Jul, 2019 | Published: 02 Aug, 2019

Citation: Cherono R, Chege P, Kimiywe J, Ogada I (2019) Body Image at Postpartum: Being Overweight but Not Noticing! Nutr Food Technol Open Access 5(1): dx.doi.org/10.16966/2470-6086.159

Copyright: (C) 2019 Cherono R, et al. This is an open-access article distributed under the terms of the Creative Commons Attribution License, which permits unrestricted use, distribution, and reproduction in any medium, provided the original author and source are credited.

\begin{abstract}
Poor dietary habits that lead to obesity may result from distorted body image where individuals fail to accurately recognize own weight status. Previous researches have shown rising trends in prevalence of overweight and obesity among women of child-bearing age. African women have generally been reported to appreciate big bodies. This study investigated accuracy of body size estimation, ideal body size and the relationship between BMI and body size underestimation among postpartum women with infants six to nine months old in Kasarani sub-county, Nairobi City, County Kenya. Randomly selected 460 postpartum women attending health facilities for vaccination/growth monitoring of their infants took part in the study. Analysis included response from 433 postpartum women. Weight and height were measured and BMI calculated. Body image was determined using Body Size Scale (BSS) with 9 female silhouettes ranging from very thin to very obese. The mothers were asked to select the body they perceived to be their current and their ideal body size. Overall, $54 \%$ of the study population was overweight or obese. Three quarter (75.2\%) of those who were overweight or obese underestimated their weight. Further, $37.6 \%$ of those who were overweight or obese desired to add weight or maintain weight. There was significant positive relationship between BMI and body size underestimation. Interventions that incorporate psychological aspects in nutrition education are necessary for postpartum women to have realistic body size goals as part of strategies to curb rise of obesity.
\end{abstract}

Keywords: Body image; Body weight dissatisfaction; Overweight; Postpartum

\section{Introduction}

Body image influences body weight regulation and may contribute to long-term nutritional status after pregnancy [1]. Prevalence of obesity among women of child-bearing age has been rising in recent past and research has found women with added weight after delivery $[2,3]$. African women however, are reported to appreciate big bodies $[4,5]$ attain higher BMI and are less reluctant to lose weight after gaining it at gestational period [6,7]. For instance, in North Carolina, African American women were found to desire bigger body sizes compared with white women [8]. This tolerance of heavier bodies may be a risk for obesity.

Body Weight Dissatisfaction (BWD) dominates the postpartum period for majority of women. After pregnancy, women struggle to regain their pre-pregnancy body size and or ideal body shapes [9]. Postpartum women have expressed dissatisfaction with their bodies; reported lack of attributory causes for being large and experienced pressure to fit the slim-ideal body shape after pregnancy [10]. Mothers' body weight dissatisfaction has been found to increase significantly from 1 to 9 months postpartum [11]. Body weight dissatisfaction may have adverse effects on both the mother and the child. BWD has been associated with higher levels of disordered eating and lower levels of breastfeeding self-efficacy $[1,5]$. Further, distorted body image has been reported to lead to poor weight control practices among postpartum women [12,13]. Although these studies show body dissatisfaction among postpartum women, data are limited on postpartum body image in East Africa.

In Kenya, a study on body image done in 2008-2009 in Nairobi slums indicated that $43.4 \%$ of women preferred bodies categorized as overweight and obese [14]. Little is however, known concerning postpartum body image of Kenyan women.

\section{Methods}

This study was part of research that investigated dietary practices, body image and nutritional status of postpartum women in Kasarani sub-county, Nairobi City County, Kenya. The study used a crosssectional analytical design with quantitative techniques in collection, analysis and presentation of data. Women 15-49 years of age with infants 6-9 months of age, residing in and attending health facilities for vaccination/growth monitoring of their infants within Kasarani 
Sub-County were included in the study. Mothers who did not give consent or were pregnant were excluded.

The sub-county has 2 divisions namely Kasarani and Embakasi North with 11 locations and 24 sub-locations [15]. It has a population of 1,98,932 of which 99,445 are female [15] and an area of $85.70 \mathrm{~km}^{2}$. A lot of informal trading activities take place in Kasarani. Kasarani subcounty was purposively selected because it is heterogeneous, densely populated and has a large number of health centres [16]. The study focused on 50 health facilities that offer vaccination services in the area. The study adopted multistage sampling technique. From lists of health facilities obtained from the vaccine dispatching centre for the sub-county, Dandora 1 health centre, four private health facilities were selected by simple random sampling and six public health facilities were purposively selected since they had large numbers of clients. Proportionate simple random sampling was then used to draw 196 participants from private and 264 from public health facilities. The proportionality was based on attendance in private and public health facilities.

Out of 460 questionnaires administered, data from a total of 433 consenting postpartum women were analysed translating to $94.1 \%$ response rate. The $5.9 \%$ were dropped out generally due to incomplete response or inconsistency to questionnaire. Interviews and all measurements were done using structured researcher guided questionnaires at the selected health facilities. The objective of the study was explained to each of the participant and signed consent obtained before the interview was conducted and the anthropometric measurements taken. Ethical approval from Kenyatta University Ethical Review Committee was sought before commencing the research. The researcher further sought permission from local administration authority and health facilities that were taking part in the study as well as from the participants.

The height and weight measurement of the participants were taken. The participants' weight was taken to the nearest $0.1 \mathrm{~kg}$ using a SECA electronic digital weighing scale while height was measured to the nearest centimetre using a SECA 213 stadiometer height rod. The reliability of all measurements was assessed and adjusted during training and pretesting of questionnaire. BMI was categorized into underweight $(<18.50)$, normal weight $(18.50-24.99)$, overweight (25$29.99)$ and obese ( $\geq 30.00$ ) based on WHO's classification [17].

Body image was assessed using Body Size Scale [18], for assessing body size perception in African population. The BSS had 9 silhouettes of females ranging from very thin to obese (Figure 1). These silhouettes were separated and coded 1 to 9 on the back from very thin to obese. The codes and the assigned anthropometric measurements were not visible to the participants. Each figure was displayed on $16 \mathrm{~cm}$ square cards on a flat surface. The silhouettes were put in a random order then probed for Current Body Size (CBS) and Desired Body Size (DBS).

\section{Data Analysis}

Statistical Package for Social Sciences (SPSS) version 20 was used for data entry, cleaning and analysis. Cleaning involved scrutiny of data for errors and questionnaires which had incomplete information were excluded. Descriptive statistics such as percentages were used to describe variables such as body weight categories and body image. The participants CBS was evaluated by asking 'Can you point out the model which represents how you look most'. The DBS was evaluated by asking 'Can you point out the individual that you most want to look like?' The CBS and DBS scores were used as the code of the photo that the participants pointed out. The participants "desire for weight change index" was calculated by subtracting CBS scores from DBS scores. A positive value indicated the desire to gain weight; a negative value, the desire to lose weight. The "body weight satisfaction index" was calculated as the absolute value of the "desire for weight change index": the higher the index value, the lower the body weight satisfaction [18].

The proportion of participants underestimating their weight in each BMI category was computed. The extent of underestimation, agreement with, or overestimation of actual body size was done by comparing BMI category with CBS category. The desire to gain weight, lose weight, or maintain weight for each BMI category was computed based on desire for weight change index. Bivariate association between BMI and participant's underestimation of BMI category was determined. The dependent variable was the participant's binary outcome whether she underestimated her body size or not (underestimation $=1$; agreement $=0$; over-estimation $=0$ ). The independent variable was the participant's BMI. Statistical significance was set at $p$ values less than 0.05 .

\section{Results}

\section{Sample characteristics}

Participants in this study had a mean age of $27.07 \pm 5.277$ years and the majority, (82\%), was married and had some level of education (70.4\%). More than half, (63.7\%), of the participants came from urban informal settlements. About half of the mothers, (49.2\%) were house wives and $47.3 \%$ earned a monthly household income of less than Kenyan Shillings (KSH) 20,000 equivalent to 200 United States Dollars (USD).

\section{Body size estimation}

In general, $2.3 \%$ participants were classified as underweight, $43.6 \%$ as normal, $32.3 \%$ as overweight and $21.7 \%$ as obese according to WHO BMI classification (Table 1). The proportion of those who perceived their current body size as underweight was $6.2 \%$; normal weight, $55.2 \%$; overweight, $25.2 \%$ while obese was $34.3 \%$.

Overall, $56.6 \%$ participants underestimated, $27.9 \%$ overestimated and only $15.5 \%$ correctly estimated their body size (Figure 2 ). Among the participants in underweight category, $10 \%$ underestimated, $80 \%$ overestimated and only $10 \%$ accurately estimated their body size. In the normal weight category, $36 \%$ underestimated, $39.7 \%$ overestimated and $24.3 \%$ accurately estimated their body size. Within the overweight category, $74.3 \%$ underestimated, $15.7 \%$ overestimated while only $10 \%$ accurately estimated their body sizes. On the other hand, in the obese category, $76.6 \%$ underestimated, $17 \%$ overestimated and merely $6 \%$ precisely estimated their body size.

Bivariate analysis was used to correlate BMI with participants' underestimation of BMI category. The dependent variable in the correlation was the participant's binary outcome whether she underestimated her body size or not (under-estimation=1; agreement $=0$; over-estimation $=0$ ). The independent variable was the participants' BMI. This analysis showed a moderate positive correlation between BMI and body size underestimation $(\mathrm{r}=0.353$; 95\% CI [0.227-0.434]; $\mathrm{p}=<0.001)$.

\section{Ideal body size}

In general, a quarter (25.4\%) of the mothers wished to add weight, $43.9 \%$ wished to reduce weight while a third (30.7\%) desired to maintain their weight (Figure 3). Within the underweight BMI category, $60 \%$ wished to add weight and $40 \%$ desired to maintain weight. In the normal weight category, $41.3 \%$ wished to add, $23.2 \%$ wished to reduce while $35.5 \%$ desired to maintain their weight. Among those classified as overweight, $16.4 \%$ wished to add, $50.7 \%$ 


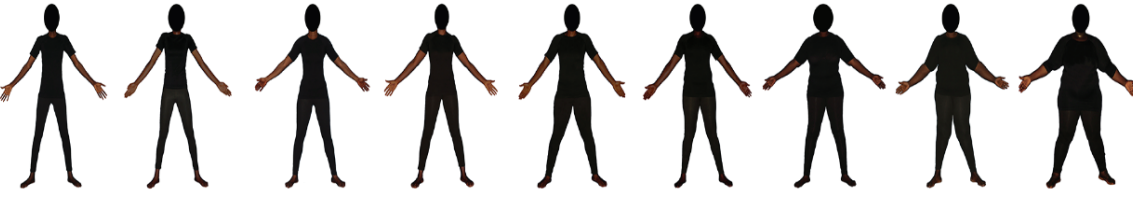

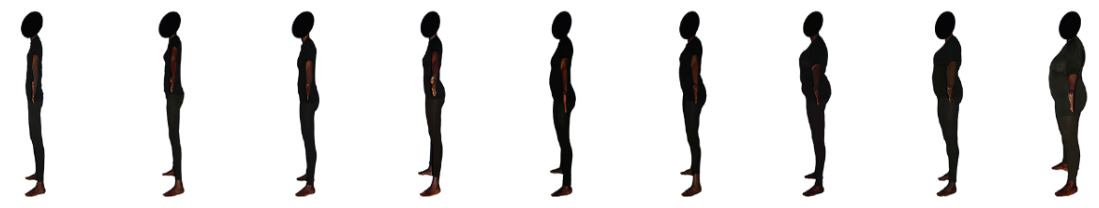

\begin{tabular}{|c|c|c|c|c|c|c|c|c|c|}
\hline 2.13 & 2.34 & 3.12 & 3.86 & 4.89 & 5.38 & 6.31 & 8.01 & 9.64 & Endomorphy \\
\hline 20.09 & 20.28 & 23.17 & 26.61 & 28.13 & 31.35 & 36.36 & 42.38 & 42.74 & Body Fat(\$) \\
\hline 16.11 & 20.02 & 21.57 & 24.09 & 25.27 & 29.88 & 33.07 & 38.78 & 49.99 & BM! \\
\hline
\end{tabular}

Figure 1: Stunkard Figure Scale [18].

Table 1: Maternal Body Mass Index and Current Body Size

\begin{tabular}{|c|c|c|}
\hline Attribute & $N(433)$ & Mean \\
\hline & \multicolumn{2}{|c|}{$n(\%)$} \\
\hline \multicolumn{2}{|l|}{ Body Mass Index } & \multirow{5}{*}{$26.29 \pm 5.06$} \\
\hline Underweight & $10(2.3)$ & \\
\hline Normal & $189(43.6)$ & \\
\hline Overweight & $140(32.3)$ & \\
\hline Obese & $94(21.7)$ & \\
\hline \multicolumn{2}{|l|}{ Current body size } & \multirow{5}{*}{$25.17 \pm 6.22$} \\
\hline Underweight & $27(6.2)$ & \\
\hline Normal & $239(55.2)$ & \\
\hline Overweight & $109(25.2)$ & \\
\hline Obese & $58(13.4)$ & \\
\hline
\end{tabular}

wished to reduce while only about a third (32.9\%) desired to maintain their weight. On the other hand, $3.2 \%$ in the obese category wished to add weight, $79.8 \%$ wished to reduce weight and almost a fifth (17\%) desired to maintain their weight.

\section{Discussion}

This study examined how body image was related with BMI at postpartum and the extent of disagreement between body image and BMI. The study population had a higher prevalence of overweight and obesity than the prevalence reported in the national survey of 2014 [17]. Evidence has shown steady rise in the prevalence of overweight and obesity among urban women of reproductive age in most African countries including Kenya [19]. Nutrition status of postpartum women may be contributing to the increase in the rate of overweight and obesity. If unchecked, such rise may pose a risk of increased NCD's which may burden the public health.

Disturbed body image might be associated with overweight and obesity [20]. Gestational process changes women's body size and weight and thus has a potential to influence Body Image Satisfaction
(BIS). In this study, only about a third (31.4\%) of the mothers was satisfied with their current body size and more mothers desired to lose weight $(43.9 \%)$ as opposed to gaining weight $(25.64 \%)$. This observation compares with high body weight dissatisfaction observed with postpartum women elsewhere [11].

This study used silhouettes to determine self-estimate of body size. Findings indicate that a large proportion of mothers had discrepancy between their body size perception and actual BMI. These discrepancies could arise from individual or societal definitions of 'desirable' or 'normal' body size that are not based on medical facts [14]. The fact that $36 \%$ of normal weight and $75.2 \%$ of the overweight and obese mothers underestimated their body sizes, confirms the evidence that black women tend to have lower perceived weight despite having higher body mass [21]. The positive correlation between BMI and underestimation of body size category further suggests a likelihood of the participants appreciating big body size. Due to underestimation of weight, almost half of the normal weight mothers wished to add weight while about a third of mothers categorized as overweight and obese desired to add weight or maintain weight. Existence of high prevalence of body size underestimation alongside a general desire to lose weight $(60.8 \%)$ among mothers categorized as overweight and obese may make attainment of healthy weight elusive.

The study determined ideal body size for each of the participants and how it related to their actual BMI. Majority of the mothers chose normal BMI category as Ideal body size yet $41.3 \%$ and $16.4 \%$ of those categorized by BMI as normal and overweight respectively desired to add weight. This observation emphasizes the fact that disturbed ability to accurately identify own body size can innocently lead to wrong body size goals and contribute to overweight and obesity [22]. Distorted body image may not only caused weight retention in postpartum women [23], [24], but can also be modeled to offspring since mothers have been found to influence the development of child's body image and BMI trajectories [25,26]. After delivery therefore, realistic body size goals may promote the motivation to lose and or control weight among postpartum mothers and contribute to higher success in attaining them $[27,28]$. 


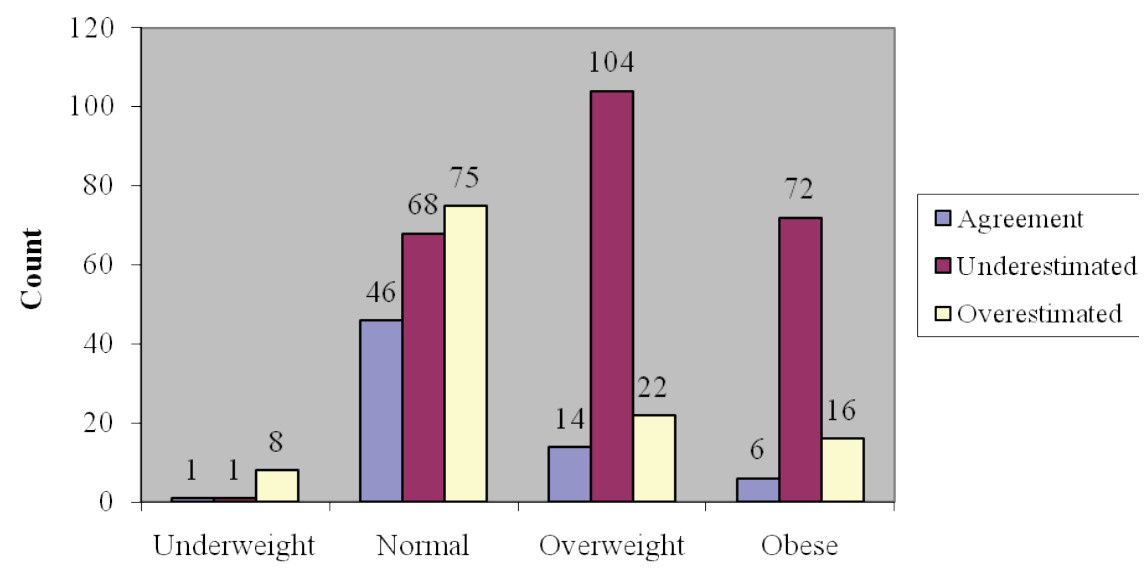

BMI category

Figure 2: Postpartum mothers' accuracy of body size estimation by BMI categories.

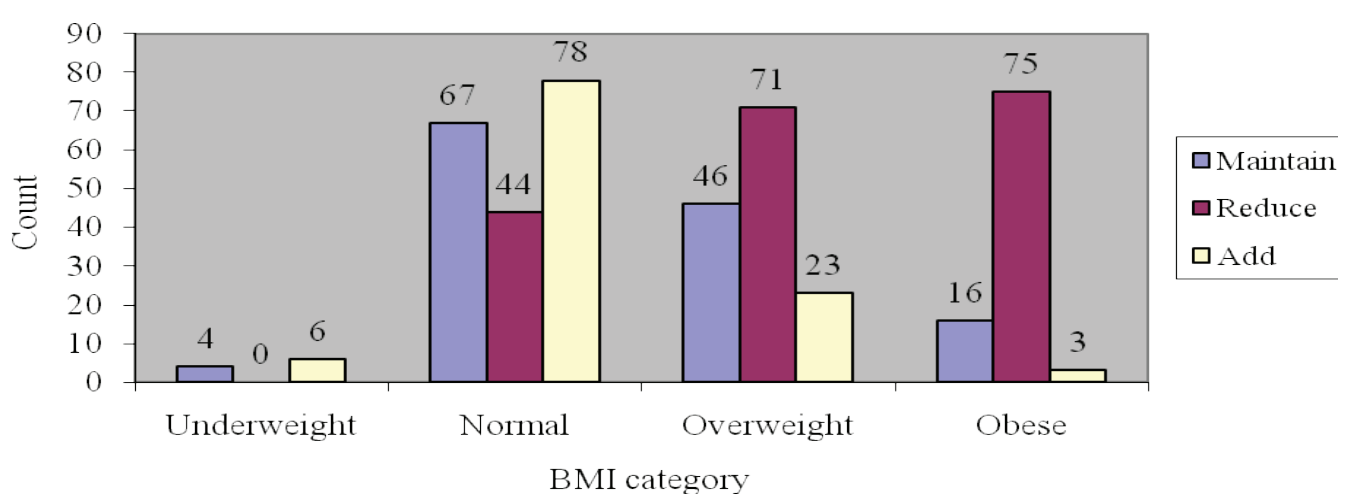

Figure 3: Desired weight change by BMI categories.

This study had one main limitation. The use of 9 discrete silhouettes to assess body image makes body size look like a continuous variable measured from a finite number of images. To reduce that impression and increase precision, this study used BSS that was already developed and validated in a previous study.

\section{Conclusion}

Majority of the mothers categorized as overweight or obese in this study underestimated their weight. This study has important implication for maternal care after delivery. The high level of overweight and obesity reported in this study alongside high prevalence of inaccurate estimation of body size calls for interventions to assist mothers accurately identify their sizes and develop realistic body size goals.

\section{Recommendations}

The study recommends that Nutritionists at health facilities carry out routine nutrition assessment of mothers at postpartum to identify those at risk of over and under malnutrition. Nutrition counselling should be provided to mothers to encourage healthy dietary habits beyond the birth of the baby.

\section{References}

1. Keen VB, Potts CS (2011) Postpartum Obesity: The Root Problem of Childhood Obesity? Forum on Public Policy Online 2011: 1-12.

2. Endres LK, Straub H, McKinney C, Plunkett B, Minkovitz CS, et al. (2016) Postpartum Weight Retention Risk Factors and Relationship to Obesity at 1 Year. Obstet Gynecol 125: 144-152.

3. Nehring I, Schmoll S, Beyerlein A, Hauner H, Von Kries R (2011) Gestational weight gain and long-term postpartum weight retention: A meta-analysis. Am J Clin Nutr 94: 1225-1231.

4. Pickett S, Peters RM (2015) Beliefs About Personal Weight Among African American Women. Clin Nurs Res 26: 191-204.

5. Thompson AL (2013) Intergenerational impact of maternal obesity and postnatal feeding practices on pediatric obesity. Nutr Rev 71: S55-S61.

6. Timilsina S, Dhakal R (2015) Knowledge on Postnatal Care Among Postnatal Mothers. Saudi J Med Pharm Sci 1: 87-92.

7. George F Winter (2016) Body image and pregnancy. Br J Midwifery 24: 8 . 
8. McCuen-Wurst C, Culnan E, Stewart NL, Allison KC (2017) Weight and Eating Concerns in Women's Reproductive Health. Curr Psychiatry Rep 19: 68.

9. Hillemeier MM, Weisman CS, Chuang C, Downs DS, McCallHosenfeld J, et al. (2011) Transition to Overweight or Obesity among women of reproductive age. J Womens Health (Larchmt) 20: 703710.

10. Boghossian NS, Yeung EH, Lipsky LM, Poon AK, Albert PS (2013) Dietary patterns in association with postpartum weight retention ${ }^{1-3}$. Am J Clin Nutr 97: 1338-1345.

11. Henriques A, Alves E, Barros H, Azevedo A (2013) Women's satisfaction with body image before pregnancy and body mass index 4 years after delivery in the mothers of generation XXI. PLoS One 8: e70230.

12. Lynch E, Liu K, Wei GS, Spring B, Kiefe C, et al. (2009) The relation between body size perception and change in body mass index over 13 years. Am J Epidemiol 169: 857-866.

13. Steyn NP, McHiza ZJ (2014) Obesity and the nutrition transition in Sub-Saharan Africa. Ann N Y Acad Sci 1311: 88-101.

14. Ettarh R, Van de Vijver S, Oti S, Kyobutungi C (2013) Overweight, obesity, and perception of body image among slum residents in Nairobi, Kenya, 2008-2009. Prev Chronic Dis 10: E212.

15. Nairobi County Government (2014) Nairobi County Integrated Development Plan.

16. Ali Nadim Zaidi (2013) Exploring Kenya's Inequality. Kenya National Bureau of Statistics. Nairobi, Kenya.

17. Department of health and human services, Centers for disease control and prevention (2011) Body mass index: Considerations for practitioners.

18. Cohen E, Bernard JY, Ponty A, Ndao A, Amougou N, et al. (2015 Development and Validation of the Body Size Scale for Assessing Body Weight Perception in African Populations. Plos One 10: e0138983.
19. Madrigal H, Sánchez-Villegas A, Martínez-González MA, Kearney J, Gibney MJ, et al. (2000) Underestimation of body mass index through perceived body image as compared to self-reported body mass index in the European Union. Public health 114: 468-473.

20. Stewart TM, Williamson DA, Smeets MA, Greenway FL (2001) Body Morph Assessment : Preliminary Report on the Development of a Computerized Measure of Body Image. Obes Res 9: 43-50.

21. Gardner RM, Friedman BN, Jackson NA (1998) Methodological Concerns When Using Silhouettes to Measure Body Image. Percept Mot Skills 86: 387-395.

22. Kenya National Bureau of Statistics (2015) Kenya Demographic and Health Survey. Kenya.

23. Amugsi DA, Dimbuene ZT, Mberu B, Muthuri S, Ezeh AC (2017) Prevalence and time trends in overweight and obesity among urban women: an analysis of demographic and health surveys data from 24 African countries, 1991-2014. BMJ Open 7: e017344.

24. Gjerdingen D, Fontaine P, Crow S, McGovern P, Center B, et al. (2010) Predictors of Mothers' Postpartum Body Dissatisfaction. Women Health 49: 491-504.

25. Marshall TA, Kramer KWO, McMahon BC, Starr DE, Phipps KR, et al. (2014) Postpartum Nutrient Intakes and Beverage Patterns of American Indian Women. The Open Access J Sci Technol 2: 101020.

26. Yang K, Turk MT, Allison VL, James KA, Chasens E (2014) Body Mass Index Self-Perception and Weight Management Behaviors During Late Adolescence. J Sch Health 84: 654-660.

27. Mbochi RW, Kuria E, Kimiywe J, Ochola S, Steyn NP (2012) Predictors of overweight and obesity in adult women in Nairobi Province Kenya. BMC Public Health 12: 823.

28. Monteiro da Silva Mda C, Marlúcia Oliveira A, Pereira Magalhães de Oliveira L, Silva dos Santos Fonseca DN, Portela de Santana ML, et al. (2013) Determinants of postpartum weight variation in a cohort of adult women; a hierarchical approach. Nutr Hosp 28: 660-70. 